\section{Y. OHSAKA ${ }^{1,2}$, H. NISHINO ${ }^{1,3}$}

${ }^{1}$ Department of Biochemistry and Molecular Biology, Graduate School of Medical Science, Kyoto Prefectural University of Medicine, 465 Kajii-cho, Kawaramachi-Hirokoji, Kamigyo-ku, Kyoto 602-8566, Japan

${ }^{2}$ Department of Pharmacology, Faculty of Pharmaceutical Sciences, Chiba Institute of Science, 15-8 Shiomi-cho, Choshi, Chiba 288-0025, Japan

${ }^{3}$ Ritsumeikan Global Innovation Research Organization, Ritsumeikan University, 1-1-1 Nojihigashi, Kusatsu, Shiga 525-8577, Japan E-mail: y-ohsaka@cis.ac.jp; y-ohsaka@live.jp

\section{POLYMORPHISMS} IN THE 5'-UTR OF PTEN AND OTHER GENE POLYMORPHISMS IN NORMAL JAPANESE INDIVIDUALS

\begin{abstract}
Polymorphisms are distributed differently in populations, including those of regions, ethnic groups, and diseased patients. In order to investigate variation in nucleotide sequences in normal individuals, we isolated genomic DNA from the blood of healthy Japanese individuals and sequenced the 5'-untranslated region (5'UTR) of the phosphatase and tensin homolog deleted on chromosome 10 (PTEN) gene and the gene promoter, intron, and exon nucleotides of $p 53, p 14^{A R F}$, murine double minute 2 (MDM2), and the $\beta_{2^{-}}$and $\beta_{3}$-adrenoceptor (-AR). We found polymorphisms in these regions, including a deletion at positions -465 to -463 and a substitution at position -404 in PTEN and a substitution at position -4924 in p14ARF, in normal individuals. Individuals with or without the PTEN polymorphism harbored a different distribution of polymorphisms, including simultaneous alterations in nucleotides of p53, MDM2, and $\beta_{3}-A R$, and also harbored some polymorphic nucleotides located in the same set of associatively altered nucleotides. Our results show that multiple nucleotides, including the PTEN nucleotides, are altered in normal Japanese individuals and provide useful information for genotyping studies in individuals and populations.
\end{abstract}

(c) Y. OHSAKA, H. NISHINO, 2012
Introduction. Control subjects harbor polymorphisms of the phosphatase and tensin homolog deleted on chromosome 10 (PTEN) gene, including those at positions $-1026,-903$ [1], and -9 [2] in the 5'-untranslated region (5'UTR). The PTEN -1026 and -903 polymorphisms are located around the binding sites of transcription factors such as Sp1 [1], and the -9 polymorphism is located close to a Kozak sequence. A polymorphism of the p53 gene in codon 72 , which is commonly found in various populations, including the Japanese population [3], is distributed latitude-dependently among resident populations of eastern Asia in areas located from $10-50^{\circ}$ north; the distribution of this polymorphism is also associated with winter temperatures [4]. In addition, an intron polymorphism at position SNP309 of the murine double minute 2 (MDM2) gene shows a different distribution among regions that are exposed to distinct levels of ultraviolet radiation [4]. A PTEN promoter polymorphism at position -1142, which is found in normal Japanese individuals, is located within a p53-binding element [5], and a $p 53$ promoter polymorphism at the -824 to -818 poly $(\mathrm{C})$ positions (a $\mathrm{C}$-to- $\mathrm{C}$ insertion polymorphism) found in a normal Japanese population [6] and the PTEN -1142 promoter polymorphism alter cellular transcriptional activity in the presence or absence of serum in culture medium [5]. PTEN gene expression is increased at $32{ }^{\circ} \mathrm{C}$ in cells expressing a temperature-sensitive p53 mutant [7] and differs among individuals, including control subjects [1] and those with nondiseased tissues $[8,9]$.

Polymorphisms are reportedly associated with individual predispositions, including those to diseases. A population-based study using polymerase chain reaction-single-strand conformational polymorphism (PCR-SSCP) and direct nucleotide sequencing analyses has shown that the -9 polymorphism in the PTEN 5'-UTR is associated with a disease of diabetes exhibiting metabolic abnormalities in a Japanese population [2]. A similar association with diabetes has also been reported for other gene polymorphisms, including a $p 14^{A R F}$ polymorphism at position -3735 , in a European population [10]. Some promoter polymorphisms within the $p 14^{A R F} 4.5 \mathrm{~kb}$ promoter, including the -3735 polymorphism, have been observed in an Asian (Korean) population [11]. Further, other association studies based on po- 
pulations or follow-up observations have shown that exon 1 polymorphisms of the $\beta_{2^{-}}$and $\beta_{3^{-}}$ adrenoceptor(-AR) genes at codons 27 and 64 are associated with not only metabolic diseases, such as diabetes and obesity [12, 13], but also other diseases, such as hypertension [14] and cancers of the breast [15] and colon [16]. In such association studies, polymorphisms are observed in control subjects who do not suffer from disease and are not necessarily observed in all of the patients.

Individuals, including non-cancer patients and normal individuals, harbor multiple nucleotide alterations in each gene; e.g., alterations in intron $1,3,4$, and 8 of the PTEN gene [17] or in exon 1 at position -628 and intron 1 at positions -466 and -215 (SNP309) of the MDM2 gene [6]. The MDM2 -628 and -466 polymorphisms observed in normal Japanese individuals are included in associative alterations in nucleotides [6], and the PTEN intron $1,3,4$, and 8 polymorphisms observed in individuals, including non-cancer patients, are involved in a highly linked sequence of nucleotides [17]. The SNP309 polymorphism of $M D M 2$ is reportedly in linkage disequilibrium with other polymorphisms of $M D M 2$ and is distributed differently between ethnic groups [18]. Similar linkage has also been shown for the p14ARF promoter polymorphisms in a Korean population [11]. An association study has reported that the presence of the -9 polymorphism of the PTEN 5'-UTR decreases the risk of some carcinomas in the absence of another PTEN intronic polymorphism (a sequence insertion of five nucleotides) in a Chinese population [19]. Polymorphic nucleotides linked with other polymorphisms are useful for genotyping studies in populations.

In the present study, in order to investigate whether normal individuals harbor other PTEN polymorphisms and whether each individual harbors multiple nucleotide alterations, we isolated genomic DNA from the blood of healthy Japanese individuals and sequenced the 5'-UTR of PTEN together with other gene promoter, intron, and exon nucleotides at positions -824 to -818 of $p 53$; position -3735 of $p 144 R F$; positions $-628,-466$, and -215 (SNP309) of MDM2; and codons 27 and 64 of $\beta_{2^{-}}$and $\beta_{3}-A R$. We also sequenced the nucleotides upstream of the
p14ARF $4.5 \mathrm{~kb}$ promoter sequence and searched polymorphic nucleotides associatively altered with other $p 14 A R F$ polymorphisms.

Materials and methods. Study subjects and genomic DNA extraction. Human peripheral blood was obtained from 21 healthy Japanese students (in which male students outnumber female students) in their early twenties who consented to have their DNA sequenced for identification of polymorphisms. Genomic DNA was extracted from whole blood with a QIAamp DNA Blood Mini Kit (Qiagen, Hilden, Germany). DNA analysis showed that the frequency of a known polymorphism $(\mathrm{NAD}(\mathrm{P}) \mathrm{H}$ :quinone oxidoreductase (NQO1) polymorphism (C609T); [20]) was similar to that previously found in control Japanese subjects (the frequency of the NQO1 polymorphism was $48 \%$ homozygous $\mathrm{C} / \mathrm{C}, 38 \%$ heterozygous $\mathrm{C} / \mathrm{T}$, and $14 \%$ homozygous $\mathrm{T} / \mathrm{T}$ ). We investigated the frequency of the examined polymorphism by using samples obtained from 12 randomly selected students (the polymorphic frequency of NQO1 was $58.3 \%$ homozygous C/C, $33.3 \%$ heterozygous $\mathrm{C} / \mathrm{T}$, and $8.3 \%$ homozygous $\mathrm{T} / \mathrm{T}$ ), and these randomly selected samples (seven individual samples in the case of the p14ARF promoter) were used to identify polymorphisms.

PCR amplification. The PTEN 5'-UTR and the promoter sequence of $p 14^{A R F}$ were amplified by PCR in a reaction mixture containing genomic DNA $(0.1 \mu \mathrm{g})$, a primer set (Table 1$)$, and DNA polymerase (KOD-Plus DNA polymerase ([21]; Toyobo, Osaka, Japan) for PTEN or PfuTurbo DNA polymerase ([22]; Stratagene, La Jolla, CA) for p14 $\mathrm{ARF}$ ) according to the manufacturer's instructions. Amplification was performed in a thermal cycler (Takara PCR Thermal Cycler MP; Takara Bio, Osaka, Japan) under the following conditions: denaturation at $94{ }^{\circ} \mathrm{C}$ for $15-30 \mathrm{~s}$, annealing at melting temperature $[\mathrm{Tm}]$ $-5{ }^{\circ} \mathrm{C}$ for $1 \mathrm{~min}$, and extension at $68-72{ }^{\circ} \mathrm{C}$ for $2 \mathrm{~min}$. For the promoter, intron, and exon regions of $p 53$ and $M D M 2$, PCR amplification was performed by using a primer set (Table 1) as described previously [6]. For the exon regions of $\beta_{2^{-}}$and $\beta_{3^{-}} A R$, PCR was performed by using the following primers as described previously $[15,23]$ : $\beta_{2}$-AR (forward primer: 5'-GAATGAGGCTTCCAGGCGTC-3'; reverse primer: $5^{\prime}$-GGCCCATGACCAGATCAGCA-3') and $\beta_{3^{-}}$ 
AR (forward primer: 5'-CGCCCAATACCGCCAACAC-3'; reverse primer: 5'-CCACCAGGAGTCCCATCACC-3').

Determination of nucleotide sequences and analysis for polymorphisms. DNA amplified by PCR (PCR products) was used for sequence reactions (for PTEN, $p 14^{A R F}, p 53$, and MDM2) to determine the polymorphic nucleotides. The sequence reactions were performed using an ABI PRISM Dye Terminator Cycle Sequencing Kit (PerkinElmer Biosystems, Foster City, CA, USA), and nucleotide sequences were determined using an ABI PRISM 377 automated DNA sequencer (Perkin-Elmer Biosystems). The nucleotide sequences were compared with DNA sequences (accession nos. AF067844, AF082338.1, X54156.1, and U39736.1) in the DNA database of NCBI
GenBank by using the basic local alignment search tool (BLAST; [24]). For the detection of sequence alterations, nucleotides were compared among individuals by using the sequence alignment editor program BioEdit (http://www.mbio. ncsu.edu/BioEdit/bioedit.html), and heterozygous nucleotide sequences were analyzed in detail by changing the horizontal scale for the alignments of allelic nucleotides.

Detection of restriction fragment length polymorphisms (RFLPS) of $\beta_{2}$ and $\beta_{3}-A R$. PCR products were treated with or without a restriction enzyme (Fnu4HI; New England Biolabs, Inc., Ipswich, MA, USA (for $\beta_{2}$-AR) or BstOI; Promega, Madison, WI, USA (for $\beta_{3}$-AR)) for $2 \mathrm{~h}$ at $37{ }^{\circ} \mathrm{C}$ in NEBuffer (New England Biolabs, Inc.) containing bovine serum albumin according to the

Table 1

Primers used for PCR and sequencing

\begin{tabular}{|c|c|}
\hline Primer position $^{1}$ & Oligonucleotide primer \\
\hline $\begin{array}{l}\text { PTEN } \\
\quad-1530 \text { to }-1507 \\
\quad-845 \text { to }-822 \\
-605 \text { to }-628 \\
-375 \text { to }-398 \\
-247 \text { to }-270 \\
-33 \text { to }-56\end{array}$ & $\begin{array}{l}\text { 5'-TCTGCGAACGATTGTGATCCGACA-3' } \\
\text { 5'-AGTTCTCTCCTCTCGGAAGCTGCA-3' } \\
\text { 5'-GAGGAAGAGGCTGCACGGTTAGAA-3' } \\
\text { 5'-GCCGCCGTGTTGGAGGCAGTAGAA-3' } \\
\text { 5'-AGAAGACGAATAATCCTCCGAACG-3' } \\
\text { 5'-AGAGAGATGGCAGAAGCTGCTGGT-3' }\end{array}$ \\
\hline $\begin{array}{l}p 14^{A R F} \\
-5322 \text { to }-5300 \\
-5009 \text { to }-4987 \\
-4050 \text { to }-4028 \\
-4773 \text { to }-4794 \\
-3267 \text { to }-3289 \\
-2986 \text { to }-2965 \\
-2702 \text { to }-2682 \\
-2300 \text { to }-2279 \\
-2532 \text { to }-2553 \\
-2157 \text { to }-2178\end{array}$ & $\begin{array}{l}\text { 5'-GTCTCCTCACAAGCATGTCAATC-3' } \\
\text { 5'-GTTACATACATGAGTTATAGGAA-3' } \\
\text { 5'-CTGGCTCTTGCTGGCCATGAAGT-3' } \\
\text { 5'-GGCAGCATTACAATATCTAGTC-3' } \\
\text { 5'-CTTCAACTGCTTGGATGAGGACC-3' } \\
\text { 5'-CTGGATAACGATGCTTCAGTCA-3' } \\
\text { 5'-TGTATATGATGTTTGCACAAC-3' } \\
\text { 5'-TACAGAGGCGGAGGCCGGCTGA-3 } \\
\text { 5'-CTATATCAGTCAGTTCTCCAGG-3' } \\
\text { 5'-TACTTATGTACTTGTTTACTTG-3' }\end{array}$ \\
\hline $\begin{array}{l}p 53 \\
-918 \text { to }-899 \\
-669 \text { to }-690\end{array}$ & $\begin{array}{l}\text { 5'-GCTGGGAGTTGTAGTCTGAA-3' } \\
\text { 5'-CATTGTTGTATTCCTGAGTGCC-3' }\end{array}$ \\
\hline $\begin{array}{l}\text { MDM2 } \\
\quad-725 \text { to }-704 \\
\quad-310 \text { to }-289 \\
+96 \text { to }+75\end{array}$ & $\begin{array}{l}\text { 5'-TCTGACCGAGATCCTGCTGCTT-3' } \\
\text { 5'-TTCGGACGGCTCTCGCGGCGGT-3' } \\
\text { 5'-AAGCTACAAGCAAGTCGGTGCT-3' }\end{array}$ \\
\hline
\end{tabular}

Indications. ${ }^{1}$ Nucleotide positions are numbered by considering the position of nucleotide $A$ at the initiation site for translation in PTEN (accession no. AF067844), nucleotide G [56] in p14ARF (accession no. AF082338.1), nucleotide G [57] in p53 (accession no. X54156.1), and nucleotide $C$ at the $5^{\prime}$ end of exon 2 [58] in MDM2 (accession no. U39736.1) as +1 . 
manufacturer's protocol and separated by $3 \%$ agarose gel electrophoresis. RFLPs were detected by using ethidium bromide and ultraviolet light, and we evaluated the sizes of the DNA fragments generated by treatment with or without the restriction enzyme; $\beta_{2}-A R$ Gln/Gln at codon 27 produces 174-, 97-, 55-, and 27-bp fragments and Gln/Glu at codon 27 produces 229-, 174-, 97-, 55-, and 27-bp fragments, and $\beta_{3}-A R$ Trp/ Trp at codon 64 produces 99-, 62-, and 30-bp fragments and Trp/Arg at codon 64 produces 161-, 99-, 62-, and 30-bp fragments.

Results. PTEN polymorphisms and nucleotide sequence variations in normal Japanese individuals. We sequenced the 5'-UTR upstream of the -9 position of PTEN and further determined other nucleotides in the promoter, intron, and exon regions of $p 53, p 14^{A R F}, M D M 2$, and $\beta_{2^{-}}$and $\beta_{3}-A R$. We detected polymorphisms in the PTEN 5'UTR (Figs 1-3, look a pasting in at the end of number) and in the other examined genes (Fig. 4 , look a pasting in at the end of number and Tables 2 and 3) in normal Japanese individuals, and we observed individual differences in these sequences (Tables 2 and 3). These sequence variations comprised deleted, substituted, and inserted nucleotides. In the PTEN 5'-UTR, we found a deletion of nucleotide $G$ (Fig. 1) (nucleotide $\mathrm{C}$ in the opposite DNA strand to the 5'-UTR sequence; Fig. 2) at positions -465 and -463 and a nucleotide substitution of $\mathrm{C}$ to $\mathrm{T}$ (Fig. 1) (G to $\mathrm{A}$ in the opposite strand to the 5'-UTR; Fig. 3) at position -404; these polymorphisms were observed in individuals I and VIII, respectively (Table. 2). These individuals also harbored a C-to-C insertion at the -824 to -818 poly(C) positions of $p 53$ (Fig. A.1, http:// cytgen.com/articles/4620024s.pdf) and a Trp-toArg substitution at codon 64 of $\beta_{3}-A R$ (Fig. A.3b) together with A-to- $\mathrm{G}$ and $\mathrm{C}$-to-T substitutions at positions -628 and -466 (Fig. A.2 a and b) or a T-to-G substitution at position -215 (SNP309) of MDM2 (Fig. A.2c) (Table 2). A Gln-to-Glu substitution of $\beta_{2}-A R$ at codon 27 (Fig. A.3a) was only observed in individual III, and this individual also harbored the $p 53$ poly $(\mathrm{C})$ and MDM2 SNP309 polymorphisms (Table 2). The $\beta_{3}-A R$ codon 64 polymorphism and the $p 53$ and MDM2 polymorphisms were simultaneously found in individuals VII and XI, in addition to
I and VIII, while other individuals (II, IV-VI, IX, X, and XII) harbored a polymorphism(s) in p53 and/or MDM2 (Table 2). An A-to-C substitution in $p 14^{A R F}$ at position -3735 was not observed in any individuals (Table 2). The polymorphic nucleotides in PTEN, p53, MDM2, and $\beta_{2^{-}}$and $\beta_{3^{-}} A R$ were not identical among all normal Japanese individuals (Table 2), but these individuals possessed the same set of associatively altered nucleotides at the MDM2 polymorphic positions -628 in exon 1 and -466 in intron 1 (the nucleotides shown as italics in Table 2). We also found a C-to-T substitution in $p 14^{A R F}$ at position -4924 (Fig. 4) by sequencing the nucleotides upstream of the p14ARF $4.5 \mathrm{~kb}$ promoters in normal individuals. Similarly, the -4924 polymorphism of p14ARF was located in associative alterations in nucleotides (types $\alpha-\gamma$ in Table 3) with other $p 14^{A R F}$ polymorphisms at positions -2610 (an A-to-T substitution; Fig. A. $4 \mathrm{a}-\mathrm{c}$ ) and -2221 to -2218 (an AA deletion; Fig. A. $4 \mathrm{~d}-\mathrm{f}$ ); the frequency of nucleotide types $\alpha-\gamma$ was $28.6 \%, 57.1 \%$, and $14.3 \%$, respectively (Table 3).

Discussion. Gene nucleotide alterations and their frequency distributions have been analyzed in various populations, including different regions, ethnic groups, and patients with diseases; however, the nucleotide variations in normal individuals are not still understood sufficiently. Some PTEN polymorphisms have been observed in control populations [17, 2, 1, 19]. In Japanese or Chinese control subjects without diabetes or carcinomas, the frequency of the PTEN 5'-UTR -9 polymorphism (nucleotide $G$ ) is $2.5 \%$ [2] and $6.5 \%$ [19], respectively. This polymorphism is also detected in a Turkish population with glioblastoma multiforme (GBM) [25], but it is not found in a Danish Caucasian population, where some intron polymorphisms have been identified and association studies for diabetes have been conducted [26]. We found other PTEN 5'-UTR polymorphisms at positions -465 to -463 and position -404 in normal Japanese individuals (Figs 1-3), and we observed these polymorphisms in $1(4.2 \%)$ and $2(8.3 \%)$ alleles, respectively, of 24 alleles (Table 2). The frequency of these PTEN polymorphisms was approximately similar to the frequency of the PTEN 5'-UTR -9 polymorphism $(2.5 \% ;[2])$ in non-diabetic Japanese subjects 
or the PTEN -1142 polymorphism in normal Japanese individuals (5.9\%; [5]). Normal Japanese individuals, including individuals I and VIII with the PTEN 5'-UTR polymorphisms at positions -465 to -463 and -404 , harbored an insertion in the $p 53$ promoter at the -824 to -818 poly $(\mathrm{C})$ positions; substitutions in MDM2 exon 1 and intron 1 at positions $-628,-466$, and -215 (SNP309) and in $\beta_{2}$ - and $\beta_{3}-A R$ exon 1 at codons 27 and 64; and a substitution or deletion in $p 14^{A R F}$ at positions $-4924,-2610$, and -2221 to -2218 (Tables 2 and 3). The frequency of the p53, MDM2, and $\beta_{2}-$ and $\beta_{3}-A R$ polymorphisms was not markedly different from that previously observed in normal Japanese individuals [6] and control subjects who visited Japanese hospitals for a checkup [27, 12, 13, 15]. The -3735 polymorphism of $p 14^{A R F}$ was not observed in our normal Japanese individuals (Table 2), and a Korean population had this polymorphism at a low frequency $\left(0.03 \%\right.$; [11]). The $\beta_{2}-A R$ codon 27 and $\beta_{3}-A R$ codon 64 polymorphisms are observed in various races, including Asians [13], Europeans [23, 28], and Caucasians [29]. The $\beta_{2}-A R$ codon 27 polymorphism is observed at a higher frequency in Caucasian populations, but the frequency of the $\beta_{3}-A R$ codon 64 polymorphism is similar to that observed in African-American and Hispanic-Latino populations [30]. Further, the MDM2 SNP309 polymorphism is distributed differently between populations, including in patients and non-diseased patients [27], distinct regions [4], and ethnic groups [31, 18]. Some polymorphic nucleotides, including those of $p 14^{A R F}$ at positions $-4256,-3631$ and -1477 , are located in associatively altered nucleotides in a Korean population [11]. Normal Japanese individuals harbor simultaneous alterations, including those in the PTEN promoter at position -1124 and the $p 15^{I N K 4 b}$ (a cyclin-dependent kinase

Table 2

PTEN, p53, p144RF, MDM2, and $\boldsymbol{\beta}_{2^{-}}$and $\beta_{3^{-}} A R$ polymorphisms

\begin{tabular}{|c|c|c|c|c|c|c|c|c|c|}
\hline \multirow{3}{*}{$\begin{array}{l}\text { Individual } \\
\text { number }\end{array}$} & PTEN & PTEN & $p 53$ & $M D M 2$ & $M D M 2$ & $M D M 2$ & $\beta_{2}-A R$ & $\beta_{3}-A R$ & p14ARF \\
\hline & $5^{\prime}$-UTR & $5^{\prime}$-UTR & Promoter & Exon 1 & Intron 1 & Intron 1 & Exon 1 & Exon 1 & Promoter \\
\hline & -465 to -463 & -404 & -824 to -818 & $-628^{1}$ & $-466^{1}$ & -215 & codon 27 & codon 64 & -3735 \\
\hline I & $3 \mathrm{G} / 2 \mathrm{G}$ & $\mathrm{C} / \mathrm{C}$ & $7 \mathrm{C} / 8 \mathrm{C}$ & $A / G$ & $C / T$ & $\mathrm{~T} / \mathrm{T}$ & Gln/Gln & Trp/Arg & $\mathrm{A} / \mathrm{A}$ \\
\hline II & $3 \mathrm{G} / 3 \mathrm{G}$ & $\mathrm{C} / \mathrm{C}$ & $7 \mathrm{C} / 8 \mathrm{C}$ & $A / A$ & $C / C$ & $\mathrm{G} / \mathrm{G}$ & Gln/Gln & Trp/Trp & $\mathrm{A} / \mathrm{A}$ \\
\hline III & $3 \mathrm{G} / 3 \mathrm{G}$ & $\mathrm{C} / \mathrm{C}$ & $7 \mathrm{C} / 8 \mathrm{C}$ & $A / A$ & $C / C$ & $\mathrm{G} / \mathrm{G}$ & Gln/Glu & Trp/Trp & $\mathrm{A} / \mathrm{A}$ \\
\hline IV & $3 \mathrm{G} / 3 \mathrm{G}$ & $\mathrm{C} / \mathrm{C}$ & $7 \mathrm{C} / 8 \mathrm{C}$ & $A / A$ & $C / C$ & $\mathrm{~T} / \mathrm{T}$ & Gln/Gln & Trp/Trp & $\mathrm{A} / \mathrm{A}$ \\
\hline V & $3 \mathrm{G} / 3 \mathrm{G}$ & $\mathrm{C} / \mathrm{C}$ & $7 \mathrm{C} / 7 \mathrm{C}$ & $A / A$ & $C / C$ & $\mathrm{~T} / \mathrm{G}$ & Gln/Gln & Trp/Trp & $\mathrm{A} / \mathrm{A}$ \\
\hline VI & $3 \mathrm{G} / 3 \mathrm{G}$ & $\mathrm{C} / \mathrm{C}$ & $7 \mathrm{C} / 8 \mathrm{C}$ & $A / G$ & $C / T$ & $\mathrm{~T} / \mathrm{T}$ & Gln/Gln & Trp/Trp & $\mathrm{A} / \mathrm{A}$ \\
\hline VII & $3 \mathrm{G} / 3 \mathrm{G}$ & $\mathrm{C} / \mathrm{C}$ & $7 \mathrm{C} / 8 \mathrm{C}$ & $A / G$ & $C / T$ & $\mathrm{~T} / \mathrm{T}$ & Gln/Gln & Trp/Arg & $\mathrm{A} / \mathrm{A}$ \\
\hline VIII & $3 \mathrm{G} / 3 \mathrm{G}$ & $\mathrm{T} / \mathrm{T}$ & $7 \mathrm{C} / 8 \mathrm{C}$ & $A / A$ & $C / C$ & $\mathrm{G} / \mathrm{G}$ & Gln/Gln & Trp/Arg & $\mathrm{A} / \mathrm{A}$ \\
\hline IX & $3 \mathrm{G} / 3 \mathrm{G}$ & $\mathrm{C} / \mathrm{C}$ & $7 \mathrm{C} / 7 \mathrm{C}$ & $A / G$ & $C / T$ & $\mathrm{~T} / \mathrm{G}$ & Gln/Gln & Trp/Trp & $\mathrm{A} / \mathrm{A}$ \\
\hline$X$ & $3 \mathrm{G} / 3 \mathrm{G}$ & $\mathrm{C} / \mathrm{C}$ & $7 \mathrm{C} / 7 \mathrm{C}$ & $G / G$ & $T / T$ & $\mathrm{~T} / \mathrm{T}$ & Gln/Gln & Trp/Trp & $\mathrm{A} / \mathrm{A}$ \\
\hline XI & $3 \mathrm{G} / 3 \mathrm{G}$ & $\mathrm{C} / \mathrm{C}$ & $8 \mathrm{C} / 8 \mathrm{C}$ & $A / A$ & $C / C$ & $\mathrm{G} / \mathrm{G}$ & Gln/Gln & Trp/Arg & $\mathrm{A} / \mathrm{A}$ \\
\hline XII & $3 \mathrm{G} / 3 \mathrm{G}$ & $\mathrm{C} / \mathrm{C}$ & $8 \mathrm{C} / 8 \mathrm{C}$ & $A / A$ & $C / C$ & $\mathrm{G} / \mathrm{G}$ & Gln/Gln & Trp/Trp & $\mathrm{A} / \mathrm{A}$ \\
\hline
\end{tabular}

Indications. Nucleotide sequences were determined by direct sequencing of PCR products or by digesting PCR products with a restriction enzyme. The sequencing reactions were performed with the primers for PTEN (positions -375 to -398 and -247 to -270 ), p53 (positions -669 to -690 ), p14ARF (positions -4050 to -4028 ), and MDM2 (positions -725 to -704 and -310 to -289 ) (Table 1), and the digested products were separated and detected on agarose gels. $3 \mathrm{G}$ and $2 \mathrm{G}$ show PTEN nucleotides GGG and GG, respectively, at positions -465 to -463 , and 7C and 8C show p53 poly $(\mathrm{C})$ nucleotides CCCCCCC and CCCCCCCC, respectively, at positions -824 to -818 . $\beta_{2}-A R$ Gln/Gln and $\beta_{3}-A R$ Trp/Trp express homozygous amino acids glutamine at codon 27 and tryptophan at codon 64 , respectively. $\beta_{2}-A R$ Gln/Glu and $\beta_{3}-A R$ Trp/Arg show heterozygous nucleotides consisting of glutamine and glutamic acid at codon 27 and of tryptophan and arginine at codon 64, respectively. ${ }^{1}$ The characters in italics indicate nucleotides that are included in a set of associatively altered nucleotides. 


\title{
CCTCCCCTCGCCCGGCGCGGTCCCGTCCGCCTCTCGCTCGCCTCCCGCCT.
}

\author{
$-465-463$

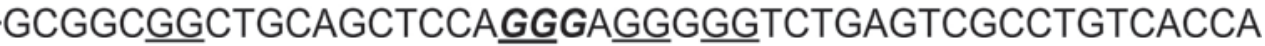 \\ $\underline{G G}$ \\ $-404$ \\ TTTCCAGGGCTGGGAACGCCGGAGAGTT $\underline{G G T C T C T C C C C T T C T A C T G C C T C ~}$

\section{ACCAGCAGCTTCTGCCATCTCTCTCCTCCTTTTTCTTCAGCCACAGGC}

Fig. 1. Polymorphic nucleotides located in the PTEN 5'-UTR. Nucleotide alterations found in normal individuals are indicated by bold italics ( $\boldsymbol{G} \boldsymbol{G}$ or $\boldsymbol{G} \boldsymbol{G}$ at positions -465 to -463 (a $\mathrm{G}$ deletion) and $\boldsymbol{C}$ or $\boldsymbol{T}$ at position -404 (a C-to-T substitution)) in the alignment of the PTEN 5'-UTR sequence deposited in GenBank (accession no. AF067844). The underlined GG dinucleotides show the distribution of the putative G-quadruplex sequences

(CDK) inhibitor) promoter at position -699 [5] or in the p53 promoter at the $\operatorname{poly}(\mathrm{C})$ positions and the MDM2 exon 1 and intron 2 nucleotides at positions -628 and -466 [6]. Correspondingly, most of the normal Japanese individuals examined in the present study had simultaneously polymorphisms at $\geq 2$ positions in PTEN, p53, p14ARF, MDM2, and $\beta_{2^{-}}$and $\beta_{3}-A R$ (Tables 2 and 3 ). In the present study, healthy Japanese individuals harbored polymorphisms in the PTEN 5'-UTR at positions -465 to -463 and -404 together with other polymorphisms in the promoter, intron, and exon regions of the other genes, and individual nucleotide alterations were distributed differently in the Japanese individuals. In addition, these individuals harbored some polymorphic nucleotides located in the same set of associatively altered nucleotides at positions, including positions $-4929,-2610$, and -2221 to -2218 of $p 14$ ARF . Our results provide helpful information for studies investigating the distribution of polymorphisms in different populations, including those of regions, races, and patients, and normal individuals.

The identification of common polymorphism patterns in the human genome has been pursued by the research community [32]. In a Korean population, some polymorphic positions in the p14ARF promoter, including position -3631 , are included in a haplotype block (a set of single-nucleotide polymorphism (SNP)alleles in a chromosomal region) [11]. Polymorphisms loca- ted in a haplotype block are useful for genotyping studies in populations with similar polymorphic alleles. The polymorphic nucleotides of MDM2 at positions -628 and -466 observed in our Japanese samples were located in the same set of associative nucleotide alterations (Table 2), similar to those previously observed in normal Japanese individuals [6]. Likewise, the $p 14^{A R F}$ -4924 polymorphism found in our samples was located in such a set of associatively altered nucleotides with other $p 14^{A R F}$ polymorphisms

Table 3 p14 ${ }^{A R F}$ polymorphic nucleotides associatively altered in normal Japanese individuals

\begin{tabular}{|c|c|c|c|c|}
\hline \multirow{2}{*}{$\begin{array}{l}\text { Polimor- } \\
\text { phic types }\end{array}$} & \multicolumn{3}{|c|}{$p 14^{A R F}$} & \multirow{2}{*}{$\begin{array}{c}\text { Frequ- } \\
\text { ency, } \\
\%\end{array}$} \\
\hline & -4924 & $-2610^{1}$ & -2218 to $-2221^{1}$ & \\
\hline Type $\alpha$ & $\mathrm{C} / \mathrm{C}$ & $\mathrm{A} / \mathrm{A}$ & $4 \mathrm{~A} / 4 \mathrm{~A}$ & 28.6 \\
\hline Type $\beta$ & $\mathrm{C} / \mathrm{T}$ & $\mathrm{A} / \mathrm{T}$ & $4 \mathrm{~A} / 2 \mathrm{~A}$ & 57.1 \\
\hline Type $\gamma$ & $\mathrm{T} / \mathrm{T}$ & $\mathrm{T} / \mathrm{T}$ & $2 \mathrm{~A} / 2 \mathrm{~A}$ & 14.3 \\
\hline
\end{tabular}

Indications. ${ }^{1}$ Genomic DNA was amplified by PCR with forward primers at positions -2986 to -2965 and -2702 to -2682 and reverse primers at positions -2532 to -2553 and -2157 to -2178 . The nucleotide sequences were determined by direct sequencing of the PCR products; the sequencing reactions were performed with the primers at positions -2702 to -2682 and -2300 to -2279 . $4 \mathrm{~A}$ and 2A show $p 14^{A R F}$ polymorphic nucleotides AAAA and AA, respectively, at positions -2218 to -2221 . 
(Table 3). On the other hand, the PTEN polymorphisms at positions -465 to -463 and -404 were not involved in the set of associative alterations (Table 2). This result appears to contrast with previous results observed by the PTEN intronic polymorphisms in non-cancer patients and tumor patients [17]. Polymorphic nucleotides associatively altered in individuals may be distributed differently within gene regions. The strength of linkage disequilibrium of the MDM2 SNP309 polymorphism with other MDM2 polymorphisms differs between Ashkenazi Jewish, Caucasian, and African-American populations [18]. The polymorphisms, including the PTEN polymorphisms, found in the current study may be candidate polymorphisms for the construction of common polymorphism patterns in populations, including other ethnic groups and diseased patients. Further investigations with a larger number of samples are needed to determine the degree of linkage strength among polymorphisms in populations.

Gene transcript analysis with a reporter gene revealed that deletion of a region of the PTEN 5 '-UTR sequence alters reporter gene expression in HEK293 cells [33]. The cellular senescenceinhibited gene (CSIG) binds to PTEN mRNA, and inhibition of CSIG gene expression by using small interfering RNA modifies the change in reporter expression following insertion of the PTEN 5'-UTR [33]. In Cos1 cells or Rat1 fibroblasts overexpressing insulin receptors, the PTEN protein level and the molecular response of Akt, a protein kinase, to treatment with insulin are differentially induced by the PTEN -9 polymorphism [2]. The alignment of G-quadruplex nucleotides binds to cellular proteins [34] and can regulate cellular gene expression [35-37]. A search for G-quadruplex motifs by using the GRSDB2 database ([38]; http://bioinformatics. ramapo.edu/GQRS/) showed that the PTEN polymorphisms are located within or around a Gquadruplex sequence (which is indicated by the underlined nucleotides GG in Fig. 1). A 5'-UTR polymorphism in BRCA2 at position - 26 reportedly alters the RNA secondary structure of the 5 '-UTR and changes gene transcription activity in HeLa and MCF-7 cells [39]. The 5'-UTR nucleotides around the PTEN polymorphisms at positions -465 to -463 are partially included in the alignment of the 5'-GGGGAGGGGG-3' sequence motif [40] or the 5'-GAGGAGGGGG-3' motif [41] located in a gene regulatory region for platelet-derived growth factor A-chain [40] or tissue inhibitor of metalloproteinase 2 (TIMP2) [41]; the TIMP2 sequence motif can interact with the Sp1 and Sp3 transcription factors [41]. We searched for transcription factors that can bind to sequences around the identified PTEN polymorphisms by using the TFSEARCH program (Searching Transcription Factor Binding Sites; http://mbs.cbrc.jp/research/db/TFSEARCH. html) with a matrix similarity of $>0.7$. We also predicted the RNA secondary structure of the PTEN 5'-UTR (from position -1031 to position -9; accession no. AF067844) with the CENTROIDFOLD program ([42]; http://www. ncrna.org/centroidfold/). TFSEARCH database analysis revealed that the PTEN polymorphisms affected the similarity of sequences of the substrates for putative transcription factors, for example, the similarity for MZF [43] at deleted nucleotide positions -465 to -463 and that for c-Rel [44] at substituted nucleotide position -404 in PTEN; similar results were also obtained by other polymorphisms (in a matrix similarity of $>0.65$ ), which affected, e.g., the similarity for TATA-binding protein at substituted or deleted positions $-4924,-2610$, and -2221 to -2218 in $p 14 A R F$. Computational assessment with the CENTROIDFOLD program showed that the RNA structure was partially altered by the PTEN polymorphisms (Fig. A.5a-c). Similarly, the PTEN 5'-UTR -9 polymorphism changed the similarity for certain transcription factors (e.g., p300; [45]) and partially altered the structure of the 5'-UTR (Fig. A.5 a and d). These results indicate that the polymorphisms, including the PTEN polymorphisms, can change the binding ability of known transcription factors to the regulatory regions and that the PTEN polymorphisms can influence the interactions of complementary nucleotide sequences.

PTEN is differentially expressed in control subjects [1] and non-tumor tissues [8,9], and PTEN gene expression has been reported to differ among patients, including those with Cowden syndrome, an autosomal dominant disorder [1], and in individual mononuclear cells from bone marrow or peripheral blood obtained from 
patients with normal acute myeloid leukemia ([46]; data shown in accession no. GSE12417 in the NCBI Gene Expression Omnibus database). Gene expression analysis with the Cancer Genome Atlas ([47]; http://cancergenome.nih.gov/) has shown that PTEN levels differ among patients with cancer, including those with GBM; a number of patients with cancer harbor somatic mutations in the exonic regions of the gene; however, other patients show different gene expression levels in the absence of these mutations. The mechanisms underlying the variable expression of PTEN among normal individuals and patients with disease remain unclear. The PTEN nucleotide alterations at polymorphic positions change transcription factor binding and affect nucleotide-nucleotide interactions in silico, and PTEN mRNA interacts with cellular protein that can alter gene expression depending on the sequence of the PTEN 5'-UTR [33]. Our results provide possible clues for clarifying the molecular machinery underlying the gene expression observed in individuals, including patients.

The polymorphisms of $M D M 2$ at position SNP309, of $\beta_{2}$ - and $\beta_{3}-A R$ at codons 27 and 64, and of $p 53$ at codon 72 are associated with individual predisposition to diseases such as diabetes [12, $23,48]$ and carcinomas [49, 27, 15, 16] in various populations, including the Japanese population. The frequency of the $\beta_{2}-A R$ polymorphism Gln/ Glu at codon 27 is increased in Caucasian females with obesity, but is decreased in obese males [29]. The $\beta_{3}-A R$ polymorphism Trp/Arg at codon 64 is associated with cardiovascular risk factors in obese Hungarian children [28]. The $p 14^{A R F}$ polymorphism at position -3631 has been associated with breast cancer in a British population [50], while the p14ARF polymorphism at -3735 is associated with diabetes in a French population with Europid ancestry [10]. The risk of chemical poisoning is associated with a polymorphism in intron 1 of p14ARF [51] and the risk of developing tumors is associated with a polymorphism in intron 4 of PTEN [19] in a Chinese population, and these associations have been shown to be dependent on the presence of another promoter polymorphism (Del1518) in the MDM2 gene [51] and the absence of the 5'-UTR -9 polymorphism in the PTEN gene [19], respectively. The simultaneous presence of other polymorphisms has also been shown to alter the degree of disease risk by gene polymorphisms $[15,49,39]$. Normal Japanese individuals did not harbor the $p 14^{A R F}-3735$ polymorphism, but harbored polymorphisms in the PTEN 5'-UTR, in the promoter poly $(\mathrm{C})$ nucleotides of $p 53$ and other promoter nucleotides of $p 14^{A R F}$, and in intron 1 and exon 1 of $M D M 2$ and $\beta_{2}$ and $\beta_{3}-A R$ (Tables 2 and 3). Individuals II, III, VI, VII, and IX-XII harbored some simultaneous alterations in $M D M 2, \beta_{2^{-}}$and $\beta_{3^{-}} A R$, and $p 53$ (Table 2), while individuals IV and $\mathrm{V}$ harbored either the p53 poly $(\mathrm{C})$ polymorphism or the MDM2 SNP309 polymorphism, respectively (Table 2). Methyl-cytosine-phospho-guanine( $\mathrm{CpG})$ sequences induced by DNA methyltransferases interact with methyl-CpG binding proteins and modulate cellular gene expression [52]. The SNP309 polymorphism of $M D M 2$ is adjacent to a $\mathrm{CpG}$ sequence. Aditionally the cellular responses of $\beta_{2}-$ or $\beta_{3}$-AR to an agonist for each receptor differ in individuals with the $\beta_{2}-A R$ codon 27 polymorphism [53] or the $\beta_{3}-A R$ codon 64 polymorphism [54]. Individuals I and VIII, with the PTEN polymorphisms, harbored simultaneously the $p 53$, $M D M 2$, and $\beta_{3}-A R$ polymorphisms (Table 2 ). A C-to-T substitution (C609T) in NQ01, which was commonly observed in our individuals, has been associated with promoter methylation of the $O^{6}$-methylguanine-DNA methyltransferase and p16 INK4a (another CDK inhibitor) genes [55]. In our individual samples, the nucleotide A in the $p 16^{I N K 4 a}$ promoter at position -191 was substituted for nucleotide $\mathrm{G}$, which is located within the $\mathrm{CpG}$ sequence (Fig. A.6 c and d). The -191 polymorphism was located in some individuals with the PTEN, MDM2, $p 53$, or $\beta_{3}-A R$ polymorphism, and the polymorphic frequency of $p 16^{I N K 4 a}$ was similar to that of NQO1 observed in our samples. Furthermore, the p16 INK4a -191 polymorphism (Fig. A.6 c and d) and the p14ARF -4924 (Fig. $4 \mathrm{~b}$ and c), -3631 (Fig. A.6 a and b), -2610 (Fig. A.4 b and c), and -2218 to -2221 (Fig. A.4 e and $\mathrm{f}$ ) polymorphisms were observed in normal individuals, including individual I harboring four polymorphisms and individual IV harboring one polymorphism (Table A.1 and some data not shown). In follow-up studies and population-based studies to determine the association of polymorphisms 
to individual predispositions, polymorphisms are useful markers of an individual's constitution and as information for personalized medicine. Our findings provide useful information for studies on the determination of polymorphism patterns that exhibit an individual's predisposition, including disease, and contribute to a better understanding of individual nucleotide variations. Further studies are needed to clarify individual differences in nucleotide sequences.

In the present study, we have shown that polymorphisms are observed in healthy Japanese individuals, including those at positions -465 to -463 and -404 of PTEN and position -4924 of $p 14^{A R F}$, and that these individuals have a different distribution of polymorphisms in the $5^{\prime}$-UTR, promoter, intron, and exon regions of PTEN, $p 53, p 14^{A R F}, M D M 2, \beta_{2}-$ and $\beta_{3}-A R$ and also harbor some polymorphic nucleotides located in the same set of associative nucleotide alterations. Most of the individuals with a nucleotide alteration harbored other polymorphisms. Our results show that multiple nucleotides, including the PTEN nucleotides, are altered in healthy Japanese individuals and provide useful information for genotyping studies in individuals and populations.

This work was supported in part by grants-inaid from the Ministry of Education, Science, and Culture of Japan, and ProBRAIN.

\section{Y. Ohsaka, H. Nishino}

ПОЛИМОРФИЗМ 5'-UTR ГЕНА РТЕN И ДРУГИЕ ГЕННЫЕ ПОЛИМОРФИЗМЫ СРЕДИ
ЗДОРОВЫХ ЯПОНСКИХ ИНДИВИДОВ

Полиморфизмы широко распространены в популяциях, включая регионы, этнические группы, а также среди больных пациентов. Для исследования изменчивости нуклеотидных последовательностей у нормальных индивидов мы выделили геномную ДНК из крови здоровых японцев и секвенировали 5'-нетранслируемый участок (5'-UTR) гена фосфатазы и гомолога тензина $(P T E N)$, промоторные последовательности, интроны и экзоны генов $p 53$ и $p 14 A R F$, ингибитора супрессора опухолевого роста $p 53$ (MDM2) и генов $\beta_{2}-$ и $\beta_{3}$-адренореце $(-A R)$. Мы обнаружили полиморфизмы в этих участках, включая делецию в положении с -465 до -463 , замену в положениях -404 в гене PTEN и -4924 вр в гене $14^{A R F}$ у нормальных индивидов. Индивиды с полиморфизмом PTEN и без него имели различное распределение полиморфных вариантов в генах $p 53, M D M 2$ и $\beta_{3}-A R$, а также содержали последовательность асоциированных полиморфных нуклеотидов. Наши результаты показывают наличие полиморфных нуклеотидов, включая полиморфизм в гене $P T E N$, среди здоровых японских индивидов, что обеспечивает перспективность исследований по генотипированию индивидов и популяционных исследований.

\section{REFERENCES}

1. Zhou X.-P., Waite K.A., Pilarski R., Hampel H., Fernandez M.J., Bos C., Dasouki M., Feldman G.L., Greenberg L.A., Ivanovich J., Matloff E., Patterson A., Pierpont M.E., Russo D., Nassif N.T., Eng C. Germline PTEN promoter mutations and deletions in Cowden/Bannayan-Riley-Ruvalcaba syndrome result in aberrant PTEN protein and dysregulation of the phosphoinositol-3-kinase/Akt pathway // Amer. J. Hum. Genet., 2003, 73, № 2, P. 404411.

2. Ishihara H., Sasaoka T., Kagawa S., Murakami S., Fukui K., Kawagishi Y., Yamazaki K., Sato A., Iwata M., Urakaze M., Ishiki M., Wada T., Yaguchi S., Tsuneki H., Kimura I., Kobayashi M. Association of the polymorphisms in the $5^{\prime}$-untranslated region of PTEN gene with type 2 diabetes in a Japanese population // FEBS Lett., 2003, 554, № 3, P. 450-454.

3. Minaguchi T., Kanamori Y., Matsushima M., Yoshikawa H., Taketani Y., Nakamura Y. No evidence of correlation between polymorphism at codon 72 of p53 and risk of cervical cancer in Japanese patients with human papillomavirus 16/18 infection // Cancer Res., 1998, 58, № 20, P. 45854586.

4. Shi H., Tan S.-J., Zhong $H ., H u W$., Levine A., Xiao C.-J., Peng Y., Qi X.-B., Shou W.-H., Ma R.-L.Z., $L i$ Y., Su B., $L u X$. Winter temperature and UV are tightly linked to genetic changes in the p53 tumor suppressor pathway in Eastern Asia // Amer. J. Hum. Genet., 2009, 84, № 4, P. 534-541.

5. Ohsaka Y., Yogosawa S., Nakanishi R., Sakai T., Nishino $H$. Polymorphisms in promoter sequences of the $p 15^{I N K} 4 B$ and PTEN genes of normal Japanese individuals // Biochem. Genet., 2010, 48, № 11/12, P. 970-986.

6. Ohsaka $Y$., Nishino $H$. Polymorphisms in promoter sequences of $M D M 2$, p53, and $p 16^{I N K 4 a}$ genes in normal Japanese individuals // Genet. Mol. Biol., 2010, 33, № 4, P. 615-626.

7. Stambolic V., MacPherson D., Sas D., Lin Y., Snow B., Jang Y., Benchimol S., Mak T.W. Regulation of PTEN transcription by p53 // Mol. Cell, 2001, 8, № 2, P. 317-325.

8. Kurasawa Y., Shiiba M., Nakamura M., Fushimi K., Ishigami T., Bukawa H., Yokoe H., Uzawa K., 


\section{Polymorphisms in the 5'-UTR of PTEN and other gene polymorphisms}

Tanzawa $H$. PTEN expression and methylation status in oral squamous cell carcinoma // Oncol. Rep., 2008, 19, № 16, P. 1429-1434.

9. Li X.-H., Zheng H.-C., Takahashi H., Masuda S., Yang X.-H., Takano $Y$. PTEN expression and mutation in colorectal carcinomas // Oncol. Rep., 2009, 22, № 4, P. 757-764.

10. Duesing K., Fatemifar G., Charpentier G., Marre M., Tichet J., Hercberg S., Balkau B., Froguel P., Gibson $F$. Strong association of common variants in the $C D K N 2 A / C D K N 2 B$ region with type 2 diabetes in French Europids // Diabetologia, 2008, 51, № 5, P. 821-826.

11. Kang M.Y., Lee B.B., Ji Y.I., Jung E.H., Chun H.-K., Song S.Y., Park S.-E., Park J., Kim D.-H. Association of interindividual differences in $p 14^{A R F}$ promoter methylation with single nucleotide polymorphism in primary colorectal cancer // Cancer, 2008, 112, № 8, P. 1699-1707.

12. Ishiyama-Shigemoto S., Yamada K., Yuan X., Ichikawa $F$., Nonaka $K$. Association of polymorphisms in the $\beta_{2}$-adrenergic receptor gene with obesity, hypertriglyceridaemia, and diabetes mellitus // Diabetologia, 1999, 42, № 1, P. 98-101.

13. Kadowaki H., Yasuda K., Iwamoto K., Otabe S., Shimokawa K., Silver K., Walston J., Yoshinaga H., Kosaka K., Yamada N., Saito Y., Hagura R., Akanuma Y., Shuldiner A., Yazaki Y., Kadowaki T. A mutation in the $\beta_{3}$-adrenergic receptor gene is associated with obesity and hyperinsulinemia in Japanese subjects // Biochem. Biophys. Res. Commun., 1995, 215, № 2, P. 555-560.

14. Strazzullo P., Iacone R., Siani A., Cappuccio F.P., Russo O., Barba G., Barbato A., D'Elia L., Trevisan M., Farinaro E. Relationship of the Trp64Arg polymorphism of the beta3-adrenoceptor gene to central adiposity and high blood pressure: interaction with age. Cross-sectional and longitudinal findings of the Olivetti Prospective Heart Study // J. Hypertens., 2001, 19, № 3, P. 399-406.

15. Huang X.-E., Hamajima N., Saito, T., Matsuo K., Mizutani M., Iwata H., Iwase T., Miura S., Mizuno T., Tokudome S., Tajima K. Possible association of $\beta_{2}$ - and $\beta_{3}$-adrenergic receptor gene polymorphisms with susceptibility to breast cancer // Breast Cancer Res., 2001, 3, № 4, P. 264-269.

16. Takezaki T., Hamajima N., Matsuo K., Tanaka R., Hirai T., Kato T., Ohashi K., Tajima K. Association of polymorphisms in the beta-2 and beta-3 adrenoceptor genes with risk of colorectal cancer in Japanese // Int. J. Clin. Oncol., 2001, 6, № 3, P. 117-122.

17. Hamilton J.A., Stewart L.M., Ajayi L., Gray I.C., Gray N.E., Roberts K.G., Watson G.J., Kaisary A.V., Snary D. The expression profile for the tumour suppressor gene PTEN and associated polymorphic markers // Brit. J. Cancer, 2000, 82, № 10, P. 16711676.

18. Atwal G.S., Bond G.L., Metsuyanim S., Papa M., Friedman E., Distelman-Menachem T., Ben Asher E., Lancet D., Ross D.A., Sninsky J., White T.J., Levine A.J., Yarden R. Haplotype structure and selection of the MDM2 oncogene in humans // Proc. Nat. Acad. Sci. USA., 2007, 104, № 11, P. 4524-4529.

19. Ge H., Cao Y.Y., Chen L.Q., Wang Y.M., Chen Z.F., Wen D.G., Zhang X.F., Guo W., Wang N., Li Y., Zhang J.H. PTEN polymorphisms and the risk of esophageal carcinoma and gastric cardiac carcinoma in a high incidence region of China // Dis. Esophagus, 2008, 21, № 5, P. 409-415.

20. Eguchi-Ishimae M., Eguchi M., Ishii E., Knight D., Sadakane Y., Isoyama K., Yabe H. Mizutani S., Greaves $M$. The association of a distinctive allele of $\mathrm{NAD}(\mathrm{P}) \mathrm{H}$ :quinone oxidoreductase with pediatric acute lymphoblastic leukemias with $M L L$ fusion genes in Japan // Haematologica, 2005, 90, № 11, P. 1511-1515.

21. Takagi M., Nishioka M., Kakihara H., Kitabayashi M., Inoue H., Kawakami B., Oka M., Imanaka T. Characterization of DNA polymerase from Pyrococcus sp. strain KOD1 and its application to PCR // Appl. Environ. Microbiol., 1997, 63, № 11, P. 4504-4510.

22. Cline J., Braman J.C., Hogrefe H.H. PCR fidelity of Pfu DNA polymerase and other thermostable DNA polymerases // Nucl. Acids Res., 1996, 24, № 18, P. 3546-3551.

23. Widén E., Lehto M., Kanninen T., Walston J., Shuldiner A.R., Groop L.C. Association of a polymorphism in the $\beta_{3}$-adrenergic-receptor gene with features of the insulin resistance syndrome in Finns // N. Engl. J. Med., 1995, 333, № 6, P. $348-351$.

24. Altschul S.F., Gish W., Miller W., Myers E.W., Lipman D.J. Basic local alignment search tool // J. Mol. Biol., 1990, 215, № 3, P. 403-410.

25. Tunca B., Bekar A., Cecener G., Egeli U., Vatan O., Tolunay S., Kocaeli H., Aksoy K. Impact of novel PTEN mutations in Turkish patients with glioblastoma multiforme // J. Neurooncol., 2007, 82, № 3, P. 263-269.

26. Hansen L., Jensen J.N., Ekstrøm C.T., Vestergaard H., Hansen T., Pedersen $O$. Studies of variability in the PTEN gene among Danish caucasian patients with Type II diabetes mellitus // Diabetologia, 2001, 44, № 2, P. 237-240.

27. Dharel N., Kato N., Muroyama R., Moriyama M., Shao R.-X., Kawabe T., Omata M. MDM2 promoter SNP309 is associated with the risk of hepatocellular carcinoma in patients with chronic hepatitis C // Clin. Cancer Res., 2006, 12, № 16, P. 4867-4871. 
28. Erhardt É., Czakó M., Csernus K., Molnaŕ D., Kosztolányi $G$. The frequency of Trp64Arg polymorphism of the $\beta_{3}$-adrenergic receptor gene in healthy and obese Hungarian children and its association with cardiovascular risk factors // Eur. J. Clin. Nutr., 2005, 59, № 8, P. 955-959.

29. Hellström L., Large V., Reynisdottir S., Wahrenberg $H$., Arner $P$. The different effects of a Gln27Glu $\beta_{2}$-adrenoceptor gene polymorphism on obesity in males and in females // J. Int. Med., 1999, 245, № 3, P. 253-259.

30. Eisenach J.H., Wittwer E.D. $\beta$-Adrenoceptor gene variation and intermediate physiological traits: prediction of distant phenotype // Exp. Physiol., 2010, 95, № 7, P. 757-764.

31. Millikan R.C., Heard K., Winkel S., Hill E.J., Heard K., Massa B., Mayes L., Williams P., Holston R., Conway K., Edmiston S., de Cotret A.R. No association between the MDM2 -309T/G promoter polymorphism and breast cancer in African-Americans or Whites // Cancer Epidemiol. Biomarkers Prev., 2006, 15, № 1, P. 175-177.

32. International HapMap Consortium. A haplotype map of the human genome // Nature, 2005, 437, № 7063, P. 1299-1320.

33. Ma L., Chang N., Guo S., Li Q., Zhang Z., Wang W., Tong T. CSIG inhibits PTEN translation in replicative senescence // Mol. Cell. Biol., 2008, 28, № 20, P. 6290-6301.

34. Wu Y., Brosh R.M. Jr. G-quadruplex nucleic acids and human disease // FEBS J., 2010, 277, № 17, P. 3470-3488.

35. Kumari S., Bugaut A., Huppert J.L., Balasubramanian $S$. An RNA G-quadruplex in the 5' UTR of the NRAS proto-oncogene modulates translation // Nat. Chem. Biol., 2007, 3, № 4, P. 218-221.

36. Kumari S., Bugaut A., Balasubramanian S. Position and stability are determining Factors for Translation Repression by an RNA G-quadruplexforming sequence within the 5' UTR of the NRAS proto-oncogene // Biochemistry, 2008, 47, №. 48, P. 12664-12669.

37. Beaudoin J.-D., Perreault J.-P. 5'-UTR G-quadruplex structures acting as translational repressors // Nucl. Acids Res., 2010, 38, № 20, P. 7022-7036.

38. Kikin O., Zappala Z., D'Antonio L., Bagga P.S. GRSDB2 and GRS_UTRdb: databases of quadruplex forming $G$-rich sequences in premRNAs and mRNAs // Nucl. Acids Res., 2007, 36, P. D141-D148.

39. Gochhait S., Bukhari S.I., Bairwa N., Vadhera S., Darvishi K., Raish M., Gupta P., Husain S.A., Bamezai R.N. Implication of BRCA2 -26G>A 5' untranslated region polymorphism in susceptibility to sporadic breast cancer and its modulation by p53 codon 72 Arg $>$ Pro polymorphism // Breast Cancer Res., 2007, 9, № 5, P. R71.

40. Liu B., Maul R.S., Kaetzel D.M. Jr. Repression of platelet-derived growth factor A-chain gene transcription by an upstream silencer element // J. Biol. Chem., 1996, 271, № 42, P. 26281-26290.

41. Zhong Z.-D., Hammani K., Bae W.S., DeClerck Y.A. $\mathrm{NF}-\mathrm{Y}$ and Sp1 cooperate for the transcriptional activation and cAMP response of human tissue inhibitor of metalloproteinases-2 // J. Biol. Chem., 2000, 275, № 24, P. 18602-18610.

42. Sato K., Hamada M., Asai K., Mituyama $T$. CENTROIDFOLD: a web server for RNA secondary structure prediction // Nucl. Acids Res., 2009, 37, P. W277-W280.

43. Morris J.F., Hromas R., Rauscher F.J. 3rd. Characterization of the DNA-binding properties of the myeloid zinc finger protein MZF1: two independent DNA-binding domains recognize two DNA consensus sequences with a common G-rich core // Mol. Cell. Biol., 1994, 14, № 3, P. 1786-1795.

44. Kunsch C., Ruben S.M., Rosen C.A. Selection of optimal kB/Rel DNA-binding motifs: interaction of both subunits of NF-kB with DNA is required for transcriptional activation // Mol. Cell. Biol., 1992, 12, № 10, P. 4412-4421.

45. Rikitake Y., Moran E. DNA-binding properties of the E1A-associated 300-kilodalton protein // Mol. Cell. Biol., 1992, 12, № 6, P. 2816-2836.

46. Metzeler K.H, Hummel M., Bloomfield C.D., Spiekermann K., Braess J., Sauerland M.-C., Heinecke A., Radmacher M., Marcucci G., Whitman S.P., Maharry K., Paschka P., Larson R.A., Berdel W.E., Büchner T., Wörmann B., Mansmann U., Hiddemann W., Bohlander S.K., Buske C. for Cancer and Leukemia Group B and the German AML Cooperative Group. An 86-probe-set gene-expression signature predicts survival in cytogenetically normal acute myeloid leukemia // Blood, 2008, 112, № 10, P. 4193-4201.

47. The Cancer Genome Atlas Research Network. Comprehensive genomic characterization defines human glioblastoma genes and core pathways // Nature, 2008, 455, № 7216, P. 1061-1068.

48. Gaulton K.J., Willer C.J., Li Y., Scott L.J., Conneely K.N., Jackson A.U., Duren W.L., Chines P.S., Narisu N., Bonnycastle L.L., Luo J., Tong M., Sprau A.G., Pugh E.W., Doheny K.F., Valle T.T., Abecasis G.R., Tuomilehto J., Bergman R.N., Collins F.S., Boehnke M., Mohlke K.L. Comprehensive association study of type 2 diabetes and related quantitative traits with 222 candidate genes // Diabetes, 2008, 57, № 11, P. 3136-3144.

49. Hong Y., Miao X., Zhang X., Ding F., Luo A., Guo Y., Tan W., Liu Z., Lin D. The role of P53 and MDM2 polymorphisms in the risk of esophageal 
squamous cell carcinoma // Cancer Res., 2005, 65, № 20, P. 9582-9587.

50. Driver K.E., Song H., Lesueur F., Ahmed S., BarbosaMorais N.L., Tyrer J.P., Ponder B.A., Easton D.F., Pharoah P.D., Dunning A.M. for the Studies in Epidemiology and Risks of Cancer Heredity (SEARCH) Team. Association of single-nucleotide polymorphisms in the cell cycle genes with breast cancer in the British population // Carcinogenesis, 2008, 29, № 2, P. 333-341.

51. Sun P., Zhang Z., Wan J., Zhao N., Jin X., Xia Z. Association of genetic polymorphisms in GADD45A, MDM2, and $p 14^{A R F}$ with the risk of chronic benzene poisoning in a Chinese occupational population // Toxicol. Appl. Pharmacol., 2009, 240, № 1, P. 66-72.

52. Deaton A.M., Bird A. CpG islands and the regulation of transcription. Genes Dev., 2011, 25, № 10, P. 1010-1022.

53. Irawan S., Budu Y., Patellongi I. The effect of olymorphysm of the $\beta-2$ adrenergic receptor on the response to $\beta-2$ agonist in bronchial asthma patients // Acta Med. Indones, 2007, 39, № 1, P. 8-12.

54. Umekawa T., Yoshida T., Sakane N., Kogure A., Kondo M., Honjyo, $H$. Trp64Arg mutation of $\beta_{3^{-}}$ adrenoceptor gene deteriorates lipolysis induced by $\beta_{3}$-adrenoceptor agonist in human omental adipocytes // Diabetes, 1999, 48, № 1, P. 117120.

55. Gilliland F.D., Harms H.J., Crowell R.E., Li Y.F., Willink R., Belinsky S.A. Glutathione S-transferase P1 and NADPH quinone oxidoreductase polymorphisms are associated with aberrant promoter methylation of $\mathrm{P} 16^{\mathrm{INK} 4 \mathrm{a}}$ and $O^{6}$-methylguanine-DNA methyltransferase in sputum // Cancer Res., 2002, 62, № 8, P. 2248-2252.

56. Robertson K.D., Jones P.A. The human ARF cell cycle regulatory gene promoter is a $\mathrm{CpG}$ island which can be silenced by DNA methylation and down-regulated by wild-type p53 // Mol. Cell. Biol., 1998, 18, № 11, P. 6457-6473.

57. Tuck S.P., Crawford L. Characterization of the human p53 gene promoter // Mol. Cell. Biol., 1989, 9, № 5, P. 2163-2172.

58. Zauberman A., Flusberg D., Haupt Y., Barak Y., Oren $M$. A functional p53 responsive intronic promoter is contained within the human $m d m 2$ gene // Nucl. Acids Res., 1995, 23, № 14, P. 2584-2592. 